\title{
A Study of Communication Protocols for Internet of Things (IoT) Devices: Review
}

\author{
Jamuna $\mathrm{M}^{1, *}$ A.M Vijaya Prakash ${ }^{2}$
}

\author{
${ }^{1}$ Dept. of ETE, BIT, Bangalore \\ ${ }^{2}$ Dept. of ECE, BIT, Bangalore \\ *Corresponding author. Email: jamuna.mrohan@gmail.com
}

\begin{abstract}
Wired and Wireless communication technology for IoT devices play an important role in various applications like transportation, healthcare systems, logistics, personal, social gaming robot, smart environment and city information. The design of low power architecture and development of the protocols is a challenging task for wireless and wired communication in IoT devices. Many communication technologies were used to improve the data rate for IoT communication but the error rate was increased, which reduces the reliability of the system. This paper focuses on various communication protocols for IoT devices. In addition, a comparison is done between different IoT communication protocols with respect to different metrics such as frequency bands, networks, topology, power consumption, data rate etc. The goal of this comparison is to present the guidelines for the researchers which help them to select the right protocol for various IoT applications.
\end{abstract}

Keywords: DDR-ECS, IoT, PIC, PDC, ECS.

\section{INTRODUCTION}

A variety of connected devices are seen to be approaching newer communication technologies because of their networks and services. Communication technologies have a major role to play in any wireless or wired network. The prerequisite for the networks comprising energy constrained devices is the need for low power communication technologies [1]. The Internet of Things is one among many new predominant concepts that offer sensors and devices connectivity to the internet which in turn furnishes everyone with connectivity, anywhere and anytime. The main perception of IoT is to empower various systems throughout the planet for sharing necessary information using modern communication technologies. Communication technologies that are employed in IoT possess minimum bandwidth, less computational power and smooth transmission among the devices, i.e. working for everyone, at any place, from any network and with any service. The communication protocols of IoT are the various means of communication that can establish ideal security to the information that is being shared between IoT connected devices. This paper aims to review and draw a comparison between different IoT communication protocols that also provide the readers with a clear comprehension of IoT communication protocols, advantages, disadvantages, power consumption \& data rate.

\section{IOT COMMUNICATION PROTOCOLS AND CLASSIFICATION}

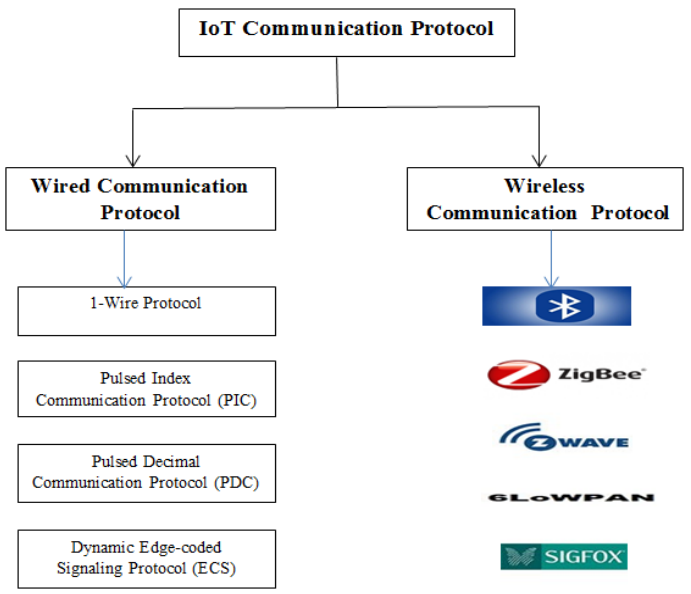

Figure 1 IoT Communication protocols

IoT is a broad area that employs a mix of Wired and Wireless forms of communication as shown in Figure1. 
The choice of the communication type in an IoT application depends on various factors such as power consumption, data transmission speed, network and data security. This section describes different IoT communication protocols.

\subsection{Wireless Communication Protocols}

The wireless communication protocols consist of guidelines in which electronic devices communicate wirelessly with other electronic devices. There exist different communication protocols which are being employed in transmission between devices in the IoT network. Wireless IoT protocol solutions, standards and technologies for data communications and connectivity come in various kinds for many potential cases of IoT applications. Some wireless protocols for IoT are discussed below.

\subsubsection{Bluetooth Technology}

Bluetooth protocol is an IEEE 802.15.1 standard for small range and low priced gadgets that are of wireless radio technology. It is a personal area network of 2.4 $\mathrm{GHz}$ meant for short-range wireless communication. Bluetooth is one of the first wireless communication protocols developed that consumes less power while replacing wired communications of short ranges (i.e. in peripherals of computer, wireless telephone equipment etc.), information sharing within the short range and portability of devices [1]. Bluetooth transmits and obtains radio waves in a range of 79 various frequencies or channels which is set on $2.45 \mathrm{GHz}$ and set apart from television, radio, mobile phones and reticent for usage by scientific, industrial and medical devices. Shortrange transmitters of Bluetooth possess power consumption that is incredibly low and are safer than wireless networks which are known to work well over longer distances (e.g.: Wi-Fi).

\subsubsection{ZigBee Protocol}

The ZigBee protocol was designed by ZigBee Alliance which is based upon low power wireless IEEE802.15.4 network standard. ZigBee serves the purpose to be an eminence that suits distinctive low-cost communication protocols devising PAN i.e., Personal area networks from minimum size, digital radios with less power that transfer the data over long ranges. It is also employed in applications that need maximum scalability, less data rate, prolonged battery power, and steady networking devices. Furthermore, this protocol also supports various topologies such as star, mesh and tree network [2] [3]. It is frequently used for applications in the home, building \& industrial automation smart metering, energy monitors at homes, data collection of medical devices, systems of traffic management and others that require lesser power and lesser bandwidth.

\subsubsection{Z-wave Protocol}

This is a low power MAC protocol designed by Zensys. It makes use of wireless home automation to bridge 30 to 50 nodes which can be used for IoT communication, most importantly in the smart home \& certain commercial domains. Z-wave protocol was developed for tiny packets of data at a minimum pace which is up to $100 \mathrm{kbps}$ and 30 -meter point-to-point communication [3] [4]. Due to this, Z-Wave is acceptable for IoT applications such as light, energy and healthcare controls. It relies on two kinds of devices slave and controlling. Slave junction assets are low cost devices that are not able to launch messages [5]. It supports mesh network topology.

\subsubsection{LoWPAN Protocol}

The protocol is a Wireless Power Area Network that has low power. This protocol underpins the IPv6 network. Here, the router forwards the information to the succeeding hop of the gateway of 6LoWPAN that is connected to 6LoWPAN with the IPv6 domain and later forwards the correct information to its steady devices, thus making it connection oriented. The address space with IPv6 is sufficient to recognize everything in the world [6]. Standard protocols [7] (TCP/IP, HTTP) are enforced directly on sensor nodes in IP-based networks, just the way it is done on the Internet with traditional web servers.

\subsubsection{Sigfox Technology}

Sigfox protocol is a low power technology that is meant for wireless communication of less energy constrained devices with different ranges such as sensors and is also meant for machine-to-machine applications. Sigfox allows the transfer of the minimum amount of information varying up to $50 \mathrm{kms}$. Sigfox makes use of the Ultra Narrow Band (UNB) technology. This protocol was specifically developed to manage less information which has a transfer speed of 10 to 1,000 bps. This technology can also babble on a small battery. Sigfox can be used in health monitoring, smart metering systems, security devices, wireless headsets, and audio applications. This technology supports the star network topology.

\subsection{Wired Communication Protocols}

Wired communication is simply defined as the communication of data through wirebased communication technology. It is also known as wireline communication. Its protocols are a set of guidelines that permit two or more elements of a 
communication system to transmit data through a material medium. We know that USB, UART, SPI, and I2C are some commonly used wired protocols. Other than these protocols here are some new wired protocols for IoT devices.

\subsubsection{1-wire Protocol}

This technology works based on a serial protocol making use of single line data and a reference ground for transmission. The master sets up the communication and runs it with one or more slave devices on the single wire bus. This protocol reinforces one slave (single drop) or many slaves (multi drop) on the bus. The transmission of data on the bus is controlled by one single master. This master establishes all the transmission on the data line which is only possible between the master and slaves [8]. Thus, information cannot be transferred between slaves. 1-wire technology is a communication system designed in a manner by which it can interface simple devices and sensors with the one wire interface. This protocol is used in communication devices that consume less power and less speed. Networks made of these devices [9] uses one wire technology and do not need any clock and data recovery (CDR) circuit [10] [11]. These types of networks are called Microlans [12] [13] that are seen in many applications of sensors [14] [15]. An important disadvantage of this protocol is that its data rate is found to be very low, limited to $16 \mathrm{Kbps}$, and is not much suitable for highly constrained IoT edge devices.

\subsubsection{Pulsed Index Communication Protocol} $(P I C)$

Pulsed-Index Communication (PIC) is a new approach that is used for communication over a single channel and depends upon the concept of transmitting the indices of $\mathrm{ON}$ bits in the form of a sequence of pulses while neglecting the OFF bits. Its name is as such since the index is transmitted as a sequence of pulses In the PIC, information is transferred on only one wire without any extra wires apart from the ground [16]. PIC involves Bit selection, Segmentation, Encoding and Decoding processes. Maximum bit rate is attained by enciphering the basic bit stream such that the code word hardly has minimum $\mathrm{ON}$ bits and these $\mathrm{ON}$ bits hold the feasible position of index. On receiving the pulses, the receiver makes use of the necessary deciphering to deduce the primitive data bits. Pulsed-Index Communication is vigorous. This protocol affords a versatile and expandable option for single-channel networking for the device's connectivity in numerous IoT applications [32-34].

\subsubsection{Pulsed Decimal Communication Protocol $(P D C)$}

PDC is PIC's modified version. It is of the same idea but with crucial developments in power consumption and data rate. This protocol is meant for achieving maximum data rate and less power dynamic signaling that does not find the need for any clock and data recovery. This novel concept [17] is developed on the principle of transferring a quantity of pulses that are equal to the number in decimal. It achieves maximum data-rate by initiating 3 step algorithm which consists of an encoding process, segmentation and a subsegmentation process. The entire process brings down the total transfer of pulses by minimizing the decimal numbers, thus enhancing the data-rate transmission. Breaking the data packet into smaller packets and transferring them as a series of pulses is the primary concern of PDC. The main advantage of this protocol is that it produces a predetermined number of symbols per data word, eventually resulting in a more reliable and simple transmission with reference to failures of packets. [34-36]

\subsubsection{Dynamic Edge-coded Signalling (ECS)}

Edge coded signaling is a newly launched protocol for single channel signaling between constrained IoT nodes. The transmitting and receiving process of standard ECS make use of a single pulse edge in adding up pulses which in turn keeps another edge inactive. ECS is more effective in which even 2 continuous data words may evolve in distinct numbers of pulses and different data-rates [18]. Bit timings and duty cycles seem to be not much important as for conventional coding methods in this edge-coding scheme. The trouble in enhancing the data rate of ECS can be achieved by making use of one and the other edges of pulses of the ECS pulse stream. This existence protocol [19] is referred to as the double data rate ECS (DDR-ECS). Both the falling and rising edge are put into use by this protocol to send an edge stream rather than a pulse stream. The transmissions toggle at every repetition of the edge stream counter and are seen to always start with a low signal level. DDR-ECS transmitter has 3 main components - Encoder, Edge stream transmitter and a control Finite state machine. Similarly, the DDRECS receiver comprises the Edge stream receiver, Decoder and a control Finite state machine. With the comparison of standard ECS, the data rate of DDR-ECS is doubled which doesn't cause any form of effect on power and area constraints [37-40].

\section{COMPARISON OF DIFFERENT PROTOCOLS AND RELATED WORKS}

This section offers researchers certain guidelines to choose the necessary communication protocol by offering comparative relations between various communication protocols. 
Table 1 Comparison of IoT Communication Protocols

\begin{tabular}{|c|c|c|c|c|c|c|c|c|c|}
\hline & \multicolumn{4}{|c|}{ Wired Protocols } & \multicolumn{5}{|c|}{ Wireless Protocol } \\
\hline Characteristics & 1-Wire Protocol & PIC Protocol & PDC Protocol & $\begin{array}{c}\text { Dynamic Edge } \\
\text { coded signaling } \\
\text { Protocol }\end{array}$ & Bluetooth & ZigBee & Z-wave & $\begin{array}{l}\text { 6LoWPAN } \\
\text { GLoWPAN }\end{array}$ & $\begin{array}{c}\text { SigFox } \\
\text { SIGFOX }\end{array}$ \\
\hline Standard & NA & NA & NA & NA & $\begin{array}{c}\text { IEEE } 802.15 .1 \\
{[20]}\end{array}$ & $\begin{array}{c}\text { IEEE } \\
802.15 .4 \\
{[20]}\end{array}$ & $\begin{array}{c}\text { Z-Wave } \\
{[20]}\end{array}$ & $\begin{array}{c}\text { IEEE 802.15.4 } \\
{[20]}\end{array}$ & $\begin{array}{l}\text { Sigfox } \\
{[21]}\end{array}$ \\
\hline Frequency Bands & NA & $\begin{array}{c}24 \mathrm{MHz} \\
{[16]}\end{array}$ & $\begin{array}{c}25 \mathrm{MHz} \\
{[17]}\end{array}$ & $\begin{array}{c}25 \mathrm{MHz} \\
{[19]}\end{array}$ & $\begin{array}{c}2.4 \mathrm{GHz} \\
{[22]}\end{array}$ & $\begin{array}{c}2.4 \mathrm{GHz} \\
{[23]}\end{array}$ & $\begin{array}{c}868 \mathrm{MHz}- \\
908 \mathrm{MHz} \\
{[24]}\end{array}$ & $\begin{array}{c}868 \mathrm{MHz}(\mathrm{EU}) \\
915 \mathrm{MHz}(\mathrm{USA}) \\
2.4 \mathrm{GHz}(\mathrm{Global})[24]\end{array}$ & $\begin{array}{c}868 \mathrm{MHz}(\mathrm{EU}) \\
902 \mathrm{MHz}(\mathrm{USA})\end{array}$ \\
\hline Network & $\begin{array}{c}\text { 1-wire Network } \\
{[8]}\end{array}$ & $\begin{array}{c}\text { Ultra-low } \\
\text { Power network } \\
{[16]}\end{array}$ & $\begin{array}{c}\text { Ultra-low } \\
\text { power network } \\
{[17]}\end{array}$ & $\begin{array}{l}\text { Ultra-low } \\
\text { power } \\
\text { network } \\
\text { [19] }\end{array}$ & WPAN [25] & WPAN[25] & WPAN[25] & WPAN [25] & LPWAN [26] \\
\hline Topology & $\begin{array}{c}\text { Master and Slave } \\
{[8]}\end{array}$ & $\begin{array}{c}\text { Master and Slave } \\
{[16]}\end{array}$ & $\begin{array}{c}\text { Master and Slave } \\
{[17]}\end{array}$ & $\begin{array}{c}\text { Master and Slave } \\
{[19]}\end{array}$ & $\begin{array}{c}\text { Star -Bus } \\
{[27]}\end{array}$ & $\begin{array}{c}\text { Star, } \\
\text { Mesh Cluster }\end{array}$ & Mesh & $\begin{array}{l}\text { Star-Mesh } \\
\text { [27] }\end{array}$ & Star \\
\hline Power & $\begin{array}{l}\text { Low power } \\
\text { protocol }\end{array}$ & $\begin{array}{c}26.6 \mu \mathrm{W} \\
{[16]}\end{array}$ & $\begin{array}{c}25 \mu \mathrm{W} \\
{[17]}\end{array}$ & $\begin{array}{c}19 \mu \mathrm{W} \\
{[19]}\end{array}$ & $\begin{array}{c}30 \mathrm{~mA} \\
\text { Low Power } \\
{[28]}\end{array}$ & $\begin{array}{c}30 \mathrm{~mA} \\
\text { Low power } \\
{[28]}\end{array}$ & $\begin{array}{c}2.5 \mathrm{~mA} \\
\text { Low power } \\
{[29]}\end{array}$ & $\begin{array}{c}\text { (1-2 years } \\
\text { lifetime on batteries) } \\
{[29]}\end{array}$ & $\begin{array}{l}10 \mathrm{~mW} \text { to } \\
100 \mathrm{~mW}\end{array}$ \\
\hline Data rate & $\begin{array}{c}16 \mathrm{Kbps} \\
{[16]}\end{array}$ & $\begin{array}{l}\text { 4.1Mbps } \\
{[16]}\end{array}$ & $\begin{array}{c}\text { 7.33Mbps } \\
{[17]}\end{array}$ & $\begin{array}{c}\text { 12Mbps } \\
{[19]}\end{array}$ & $1 \mathrm{Mbps}$ & $250 \mathrm{Kbps}$ & $\begin{array}{l}40 \mathrm{Kbps} \\
{[30]}\end{array}$ & $250 \mathrm{Kbps}$ & $\begin{array}{l}100 \text { bps- } \\
600 \text { bps }\end{array}$ \\
\hline $\begin{array}{c}\text { Common } \\
\text { Applications }\end{array}$ & $\begin{array}{c}\text { IoT Sensor } \\
\text { Applications } \\
{[16]}\end{array}$ & $\begin{array}{l}\text { IoT Sensor } \\
\text { Applications } \\
{[16]}\end{array}$ & $\begin{array}{c}\text { IoT Sensor } \\
\text { Applications } \\
{[17]}\end{array}$ & $\begin{array}{l}\text { IoT Sensor } \\
\text { Applications } \\
\text { [19] }\end{array}$ & \begin{tabular}{|c} 
Wireless \\
headsets, Audio \\
Applications \\
{$[31]$}
\end{tabular} & \begin{tabular}{|c|} 
Controlling and \\
Monitoring Home \\
industry \\
{$[31]$} \\
\end{tabular} & $\begin{array}{c}\text { Home Monitoring and } \\
\text { Controlling [31] }\end{array}$ & $\begin{array}{l}\text { Monitor and Control } \\
\text { through the internet [31] }\end{array}$ & $\begin{array}{c}\text { Energy meters \& Street } \\
\text { Lighting }\end{array}$ \\
\hline
\end{tabular}


Distinct measures are considered to enumerate the comparison between the communication protocols. Such measures include network, standard, topology, power consumption and data-rate. With respect to power consumption, wireless protocol 6LoWPAN, ZigBee, Bluetooth and Z-Wave are advised for compact devices and restricted battery power whereas with respect to wired protocols, Dynamic Edge coded signalling protocol provides low power consumption. With respect to the data-rate, Bluetooth, 6LoWPAN, ZigBee, Sigfox and $\mathrm{Z}$-Wave has data-rate less than or equal to $1 \mathrm{Mbps}$, whereas, Edge coded signalling protocol possess an average data-rate of $12 \mathrm{Mbps}$. In wired protocols, ECS is the newly introduced and the best protocol for signalling between constrained IoT nodes. Table 1 shows the comparison of both wired and wireless communication protocols with respect to different factors such as power, data rate, frequency bands, topology and applications [41-45].

\section{CONCLUSION}

As there are numerous wireless technologies in the IoT network, every technology has precise stipulations and benefits. However, it is a bit difficult to conclude which technology is more efficient. Hence, the question that someone needs to answer is "which technology or protocol is the best"? With this perspective, the present work evaluates and brings a comparison between conventional communication protocols found in IoT networks. Various metrics are employed to draw the comparison between different communication protocols which include networks, topologies, frequency, data rate and power consumption. Though a wireless protocol offers less power consumption, the data rate is in a few Kbps, whereas wired protocols offer both less power and a high data rate in the range of Mbps for IoT device communication. This paper concludes that wired protocols are best suited for IoT sensor applications offering key improvements in data rate and power consumption

\section{REFERENCES}

[1] Aqeel-ur-Rehman, Kashif Mehmood, \& Ahmed Baksh 2013, Communication Technology That Suits IoT- A Critical Review.

[2] Samie, F., Bauer, L. \& Henkel, J. 2016. IoT technologies for Embedded Computing: A survey Hardware/Software Co-design and System Synthesis (CODES+ ISSS), 2016.

[3] Salman, T. 2015. Internet of Things Protocols and Standards.

[4] Affairs, M. of E. n.d. 2015.Internet of Things in the Netherlands Applications trends and potential impact on radio spectrum.
[5] Azamuddin Bin Ab Rahman, R. J. 2015 Comparison of Internet of Things (IoT) Data Link Protocols.

[6] Petrie, C.: The Future of the Internet is Coordination. In: Proceedings of FES-2010: Future Enterprise Systems Workshop (2010).

[7] Ee, G. K., Ng, C. K., Noordin, N. K., Ali, B. M.: A Review of 6LoWPAN Routing Protocols. In: Proceeding of Asia Pacific Advanced Network (2010)

[8] MAXIM Integrated, Design resources/Technical documents/ Tutorials: Guide to 1- wire Communication

[9] MAXIM, One Wire Viewer User's Guide, Version 1.4, AN3358, Sep 2009.

[10] MAXIM, Reading and Writing 1-Wire® Devices through Serial Interfaces, AN74, June 2009.

[11] Bernhard Linke, Overview of 1-Wire ${ }^{\circledR}$ Technology and Its Use, MAXIM, AN1796, June 2008.

[12] S. Wang, K.W.E. Cheng, and K. Ding, "Design of the Temperature and Humidity Instrument Based on 1-wire Sensor for Electric Vehicle Motors," International Conference on Power Electronics Systems and Applications, pp. 1-5, May 2009.

[13] B. Huang, J. Lei, and Y. Bo, "The Reading Data Error Analysis of 1wire Bus Digital Temperature Sensor DS18B20," International Conference on Modelling, Identification and Control, Wuhan, China, pp. 433-436, June 2012.

[14] Hongmei Xue, "Research and Development of A Intelligent Temperature-Measuring System Based On 1-wire Bus," International Conference on Intelligent Computation Technology and Automation, vol. 2, pp. 30-33, October 2008.

[15] J. Dudak, G. Gaspar, and G. Michalconok, "Extension of 1-Wire Measuring System SenSys," Juraj Dudak, Gabriel Gaspar, and German Michalconok, International Symposium, pp. 1-4, December 2012.

[16] Shahzad Muzaffar, Ayman Shabra, Jerald Yoo, and Ibrahim (Abe) M. Elfadel. A Pulsed-index technique for single-channel, Low power, Dynamic signalling. Design, Automation and Test In Europe (DATE), 1485-1490, March 2015.

[17] S. Muzaffar and I. M. Elfadel, “A Pulsed-Decimal Technique for Single channel, Dynamic Signalling for IoT Applications," in 25th IFIP/IEEE International Conference on Very Large Scale Integration (VLSI-SoC 2017), Abu Dhabi, UAE, Oct. 2017, pp. 1-6. 
[18] S. Muzaffar and I. M. Elfadel, "Dynamic Edgecoded Protocol for Low power, Device-to-Device Communication," ACM Transactions on Sensor Networks (TOSN), 2020.

[19] S. Muzaffar and I. M. Elfadel, "Double data rate Dynamic Edge-coded Signalling for Low power, IoT Communication", in 27th IFIP/IEEE International Conference on Very Large Scale Integration, 2019.

[20] Kuzlu, M., Pipattanasomporn, M. \& Rahman, S. 2015. Review of communication technologies for smart homes/building applications. Innovative Smart Grid Technologies-Asia (ISGT ASIA), 2015 IEEE: $1-6$.

[21] Raza, U., Kulkarni, P. \& Sooriyabandara, M. 2017. Low Power Wide Area Networks: An Overview. IEEE Communications Surveys $\backslash \&$ Tutorials.

[22] López, P., Fernández, D., Jara, A. J. \& Skarmeta, F. 2013. Survey of Internet of Things technologies for clinical environments. Advanced Information Networking and Applications Workshops (WAINA), 2013 27th International Conference on: 1349-1354.

[23] Samuel, S. S. I. 2016. A review of connectivity challenges in IoT-smart home. Big Data and Smart City (ICBDSC), 2016 3rd MEC International Conference on: $1-4$.

[24] Gomez, C. \& Paradells, J. 2010. Wireless home Automation networks: A survey of Architectures and technologies. IEEE Communications Magazine, 48(6).

[25] Azamuddin Bin Ab Rahman, R. J. 2015. Comparison of Internet of Things (IoT) Data Link Protocols.

[26] Martha Zemede, K. T. 2015. Explosion of the Internet of Things: What does it mean for Wireless devices? Key sight Technologies.

[27] Tabish, R., Mnaouer, A. B., Touati, F. \& Ghaleb, A.M. 2013. A comparative analysis of BLE and 6LoWPAN for U-HealthCare applications. GCC Conference and Exhibition (GCC), 2013 7th IEEE: 286-291. [28] Hughes, J., Yan, J. \& Soga, K. 2015. Development of wireless sensor network using Bluetooth low energy (BLE) for construction noise monitoring. International Journal on Smart Sensing and Intelligent Systems, 8(2):1379- 1405.

[29] Aragues, A., Del Valle, P., Muñoz, P., Escayola, J. \& Trigo, J. D. 2012. Trends in entertainment, home automation and e-health: Toward cross-domain integration. IEEE Communications Magazine, 50(6).
[30] Al-Fuqaha, A., Guizani, M., Mohammadi, M., Aledhari, M. \& Ayyash, M. 2015. Internet of things: A survey on enabling technologies, protocols, and applications. IEEE Communications Surveys $\backslash \&$ Tutorials, 17(4): 2347-2376.

[31] Frenzel, L. 2012. The Fundamentals of Short Range Wireless Technology. ELECTRONIC DESIGN, Oct, 11.

[32] Kumar, M. Keerthi, B. D. Parameshachari, S. Prabu, and Silvia liberata Ullo. "Comparative Analysis to Identify Efficient Technique for Interfacing BCI System." In IOP Conference Series: Materials Science and Engineering, vol. 925, no. 1, p. 012062. IOP Publishing, 2020.

[33] Arun, M., E. Baraneetharan, A. Kanchana, and S. Prabu. "Detection and monitoring of the asymptotic COVID-19 patients using IoT devices and sensors." International Journal of Pervasive Computing and Communications (2020).

[34] Le, Ngoc Tuyen, Jing-Wein Wang, Duc Huy Le, Chih-Chiang Wang, and Tu N. Nguyen. "Fingerprint enhancement based on tensor of wavelet subbands for classification." IEEE Access 8 (2020): 6602-6615.

[35] Naeem, Muhammad Ali, Tu N. Nguyen, Rashid Ali, Korhan Cengiz, Yahui Meng, and Tahir Khurshaid. "Hybrid Cache Management in IoTbased Named Data Networking." IEEE Internet of Things Journal (2021).

[36] Pham, Dung V., Giang L. Nguyen, Tu N. Nguyen, Canh V. Pham, and Anh V. Nguyen. "Multi-topic misinformation blocking with budget constraint on online social networks." IEEE Access 8 (2020): 78879-78889.

[37] Subramani, Prabu, K. Srinivas, R. Sujatha, and B. D. Parameshachari. "Prediction of muscular paralysis disease based on hybrid feature extraction with machine learning technique for COVID-19 and post-COVID-19 patients." Personal and Ubiquitous Computing (2021): 1-14.

[38] Kumar, M. Keerthi, B. D. Parameshachari, S. Prabu, and Silvia liberata Ullo. "Comparative Analysis to Identify Efficient Technique for Interfacing BCI System." In IOP Conference Series: Materials Science and Engineering, vol. 925, no. 1, p. 012062. IOP Publishing, 2020.

[39] Parameshachari, B. D., H. T. Panduranga, and Silvia liberata Ullo. "Analysis and computation of encryption technique to enhance security of medical images." In IOP Conference Series: 
Materials Science and Engineering, vol. 925, no. 1, p. 012028. IOP Publishing, 2020.

[40] Y. Sun, J. Liu, K. Yu, M. Alazab, K. Lin, "PMRSS: Privacy-preserving Medical Record Searching Scheme for Intelligent Diagnosis in IoT Healthcare", IEEE Transactions on Industrial Informatics, doi: 10.1109/TII.2021.3070544.

[41] N. Shi, L. Tan, W. Li, X. Qi, K. Yu, "A Blockchain-Empowered AAA Scheme in the Large-Scale HetNet", Digital Communications and Networks, https://doi.org/10.1016/j.dcan.2020.10.0 02.

[42] C. Feng et al., "Efficient and Secure Data Sharing for 5G Flying Drones: A Blockchain-Enabled Approach," IEEE Network, vol. 35, no. 1, pp. 130137, January/February 2021, doi: 10.1109/MNET.011.2000223

[43] L. Tan, H. Xiao, K. Yu, M. Aloqaily, Y. Jararweh, "A Blockchain-empowered Crowdsourcing System for 5G-enabled Smart Cities", Computer Standards $\&$ Interfaces, https://doi.org/10.1016/j.csi.2021.10351 7

[44] Z. Guo, Y. Shen, A. K. Bashir, M. Imran, N. Kumar, D. Zhang and K. Yu, "Robust Spammer Detection Using Collaborative Neural Network in Internet of Thing Applications", IEEE Internet of Things Journal, vol. 8, no. 12, pp. 9549-9558, 15 June15, 2021, doi: 10.1109/JIOT.2020.3003802.

[45] K. Yu, L. Lin, M. Alazab, L. Tan, B. Gu, "Deep Learning-Based Traffic Safety Solution for a Mixture of Autonomous and Manual Vehicles in a 5G-Enabled Intelligent Transportation System", IEEE Transactions on Intelligent Transportation Systems, doi: 10.1109/TITS.2020.3042504. 